\title{
The Relationship of Individual, Occupational and Psychological Factors With Low Back Pain Among Steel Industry Workers
}

\section{Fatemeh Ahmadi}

Mashhad University of Medical Sciences

Habibollah Esmaily

Mashhad University of Medical Sciences

Seyedeh Paria Pakdaman

Mashhad University of Medical Sciences

Ehsan Rafeemanesh ( $\nabla$ Rafeemaneshe@mums.ac.ir)

Mashhad University of Medical Sciences

\section{Research Article}

Keywords: Low back pain, Risk factors, Occupational status, Occupational Stress

Posted Date: May 7th, 2021

DOI: https://doi.org/10.21203/rs.3.rs-436901/v1

License: (c) (i) This work is licensed under a Creative Commons Attribution 4.0 International License. Read Full License 


\section{Abstract}

Objectives: Low back pain (LBP) is one of the most common and most costly work-related musculoskeletal disorders. There are numerous factors that may affect the development of this disease. The aim of this study was to determine the prevalence of low back pain (LBP) and its association with individual, occupational and psychosocial factors among steel industry workers.

Methods: For this cross-sectional study, 273 workers in a steel plant were selected by random sampling method. The participants were divided into production $(n=168)$ and administrative $(n=105)$ Workers. Data was collected through in-person interview, physical examination, modified Nordic questionnaire and Osipow questionnaire. Data was analyzed by descriptive statistical methods, chi-square test, tstudent】test and logistic regression model using SPSS-20 software. In all statistical analysis $P$ value $\leq$ 0.05 was considered as statistically significant.

Results: Despite the young age of participants $(39.63 \pm 6.32$ years) and their short employment duration, the prevalence of LBP was high (38.5\%) in this industry. Gender, body mass index, smoking status and total stress score were similar in two groups. No significant relationship was found between LBP and current job status. However, LBP prevalence was significantly associated with age and duration of employment $(P<0.05)$.

Conclusion: In our study no association was observed between LBP and the participants' current job status and work- related stress. It appears that life style modifications along with education can decrease the rate of low back pain and its risk factors in employees of this industry.

\section{Introduction}

Low back pain (LBP) is among the most prevalent musculoskeletal disorders with an annual incidence of $5-14 \%$ in the general population and is now considered a modern epidemic (1). Moreover, LBP is the third cause of disability-adjusted life years (DALY) among non-communicable diseases. The most common age spans for the occurrence of LBP are the third, fourth, and fifth decades of life, making this disease the most common cause of disability in people under 45 years old (2). No exact statistical data is available in Iran regarding the LBP however, according to the reports of the Non-Communicable Diseases Center of the Ministry of Health of Iran, LBP accounts for $7.5 \%$ of the national burden of diseases in Iran (3). Furthermore, the years lost due to disability (YLD) related to LBP in all age groups is around $83 \%$ in Iran, which is approximately twice the global average in the recent 20 years (4). Despite the high incidence of LBP it is usually healed spontaneously and recovery is expected after 2 weeks in at least $50 \%$, and after 6 weeks in $90 \%$ of the patients. However, recurrence is common and is reported in 40 to $70 \%$ of the cases. It is reported that LBP becomes chronic in two to seven percent of these patients (2). Spinal disorders results in 175.8 million job restrictions and unemployment worldwide (5). Due to the detrimental effects of LBP on patients' daily life and career as well as their physical and psychological wellbeing, it is considered as one of the most important and crucial concerns of every society. 
Since LBP imposes huge costs on healthcare systems, researchers are now trying to focus on diagnosis and assessment of different types of LBP to help in designing an effective treatment strategy (1). Different factors associated with LBP are categorized into changeable and unchangeable factors. Nutrition, physical activity, smoking, weight, and ergonomic elements of the workplace are among the changeable factors. While age, sex, skeletal deformities and endogenous factors are considered as unchangeable factors (6). According to the previous studies, LBP is more prevalent in some occupations including industrial workers, nurses and drivers (7). Some factors such as lifting, whole-body vibration, awkward postures, heavy physical work and static work are mentioned as work-related factors contributing to LBP (8). However, studies conducted in the field of LBP are not conclusive regarding the causal factors of this disease; in addition, psychosocial factors and job stress were overlooked in several studies.

Identifying different risk factors of LBP incidence and factors leading to chronic LBP enables us to identify susceptible individuals. This will also facilitate planning and implementing proper preventive measures to hinder the occurrence of some of the associated problems, especially in industrial and hazardous environments. Therefore, here we sought to investigate the association between LBP and three different categories of individual, occupational, and psychosocial factors including job stress.

\section{Materials And Methods Participants}

This study was conducted on 273 people working in a steel factory in 2016. First, individuals were randomly selected according to their personnel number. Inclusion and exclusion criteria were then considered and the ones who were not eligible for the study were excluded and replaced by other workers. Inclusion criteria were willingness to participate in the study and having at least two years of working experience. Exclusion criteria included a history of any kind of LBP prior to their employment, trauma to their spine, congenital musculoskeletal diseases, and psychological disorder in the preplacement examination.

In the next step, participants were divided into two groups based on their type of work and duties: industrial workers and administrative employees. Participants who spent at least two-thirds of their working hours in an office were regarded as administrative employees. Other staff performing heavy physical tasks in different sections such as furnaceing, melting, welding, casting, etc. for at least twothirds of their working shift were considered as industrial workers. The duration of each working shift in this study was 8 hours.

\section{Data collection}

Required data were gathered through in-person interviews, physical examination, archived medical records and two questionnaires (Nordic questionnaire and Osipow job stress questionnaire).

Demographic data were extracted from workers' medical records. The two questionnaires were completed 
under the supervision of a trained occupational health professional. Osipow questionnaire is designed according to the work role and is divided into six subgroups of workload including role ambiguity, role insufficiency, role conflicts, responsibility, and work environment. This questionnaire is comprised of 10 questions in each subgroup. Answers are based on a five point Likert scale and are allocated with scores ranging from one to five. The scores from all the questions are summed and then interpreted by the questionnaire guide as followed: mild stress (scores of 60-119), mild to moderate stress (171-120), moderate to severe stress (180-239), and severe stress (240-300). The reliability and validity of this questionnaire were established before (9). In this study, we combined the first two groups (mild and mild to moderate stress) into one group titled "mild to moderate stress" and the second two groups (moderate to severe and severe) into another group titled "moderate to severe stress". In the modified Nordic questionnaire, LBP within the previous 12 months is investigated. Experts have confirmed the reliability and validity of this questionnaire (10).

In order to confirm the LBP diagnosis, all of the participants were examined by an occupational medicine specialist. In the next step, the patients were categorized into the following groups based on their medical history, physical examination and MRI findings: patients with disco-genic LBP (DLBP) and patients with nonspecific LBP (NSLBP).

NSLBP is a kind of pain localized in the lower part of the spine, not originated from a specific structure, and cannot be related to a specific disease (exp. fractures, cancers, inflammatory diseases, etc.).

\section{Statistical analysis}

The collected data were analyzed using SPSS version 20. For analyzing the data, qualitative statistical methods were used such as central measures, frequency distribution and measures of variation. Regarding the associations between different factors, chi-squared test, t-student test, and in case of the absence of normal distribution Mann-Whitney test were applied. In order to control for confounding factors, logistic regression was used. The significance level for $P$ value was considered 0.05 in all of the statistical analyses.

\section{Results}

This study recruited 273 subjects including 247 males (92.5\%) and 20 females (7.5\%). The average age of the participants was $39.63 \pm 6.32$ years. 168 individuals $(61.5 \%)$ were industrial workers and 105 subjects (38.5\%) were administrative employees. 261 people (96.3\%) were non-smokers while, 10 subjects (3.7\%) had a history of smoking. 150 subjects (54.9\%) were shift-workers. Regarding medical history, 105 subjects (38.5\%) reported low back pain (LBP) and 17 individuals (6.3\%) had psychiatric disorders.

Furthermore, the average of total stress score among all participants was $183.74 \pm 27.01$. 121 subjects (44.3\%) had mild to moderate stress level and 152 individuals $(55.7 \%)$ had moderate to severe stress 
levels. According to the analysis no significant statistical relation was observed between LBP and qualitative variables [Table 1]. 
Table 1

The Comparison of Qualitative Variables in Patients with and without LBP

\begin{tabular}{|c|c|c|c|c|}
\hline Variable & $\begin{array}{l}\text { With } \\
\text { LBP } \\
\text { N (\%) }\end{array}$ & $\begin{array}{l}\text { Without LBP } \\
\mathrm{N}(\%)\end{array}$ & $\begin{array}{l}\text { Total } \\
\mathrm{N}(\%)\end{array}$ & Test Result \\
\hline $\begin{array}{l}\text { Gender } \\
\text { Male } \\
\text { Female } \\
\text { Total }\end{array}$ & $\begin{array}{l}94 \\
(38.1) \\
9 \\
(45.0) \\
103 \\
(38.6)\end{array}$ & $\begin{array}{l}153(61.9) \\
11(55.0) \\
164(61.4)\end{array}$ & $\begin{array}{l}247 \\
(100) \\
20 \\
(100) \\
267 \\
(100)\end{array}$ & $\begin{array}{l}P \text { value }= \\
0.54 \\
x^{2}=0.376\end{array}$ \\
\hline $\begin{array}{l}\text { Occupation } \\
\text { Industrial } \\
\text { Administrative } \\
\text { total }\end{array}$ & $\begin{array}{l}67 \\
(39.9) \\
38 \\
(36.2) \\
105 \\
(38.5)\end{array}$ & $\begin{array}{l}101(60.1) \\
67(63.8) \\
168(61.5)\end{array}$ & $\begin{array}{l}168 \\
(100) \\
105 \\
(100) \\
273 \\
(100)\end{array}$ & $\begin{array}{l}P \text { value }= \\
0.54 \\
x^{2}=0.372\end{array}$ \\
\hline $\begin{array}{l}\text { Smoking } \\
\text { No } \\
\text { Yes } \\
\text { total }\end{array}$ & $\begin{array}{l}102 \\
(39.1) \\
3 \\
(30.0) \\
105 \\
(38.7)\end{array}$ & $\begin{array}{l}159(60.9) \\
7(70.0) \\
166(61.3)\end{array}$ & $\begin{array}{l}261 \\
(100) \\
10 \\
(100) \\
271 \\
(100)\end{array}$ & $\begin{array}{l}\text { Fisher's } \\
\text { Exact Test: } \\
P \text { value }= \\
0.745\end{array}$ \\
\hline $\begin{array}{l}\text { Shiftwork } \\
\text { Yes } \\
\text { No } \\
\text { total }\end{array}$ & $\begin{array}{l}60 \\
(40.0) \\
45 \\
(36.6) \\
105 \\
(38.5)\end{array}$ & $\begin{array}{l}90(60.0) \\
78(63.4) \\
168(61.5)\end{array}$ & $\begin{array}{l}150 \\
(100) \\
123 \\
(100) \\
273 \\
(100)\end{array}$ & $\begin{array}{l}P \text { value }= \\
0.56 \\
x^{2}=0.333\end{array}$ \\
\hline $\begin{array}{l}\text { Psychiatric } \\
\text { disease } \\
\text { Yes } \\
\text { No } \\
\text { total }\end{array}$ & $\begin{array}{l}9 \\
(52.9) \\
96 \\
(37.8) \\
105 \\
(38.7)\end{array}$ & $\begin{array}{l}8(47.1) \\
158(62.2) \\
166(61.3)\end{array}$ & $\begin{array}{l}17 \\
(100) \\
254 \\
(100) \\
271 \\
(100)\end{array}$ & $\begin{array}{l}P \text { value }= \\
0.21 \\
x^{2}=1.540\end{array}$ \\
\hline
\end{tabular}




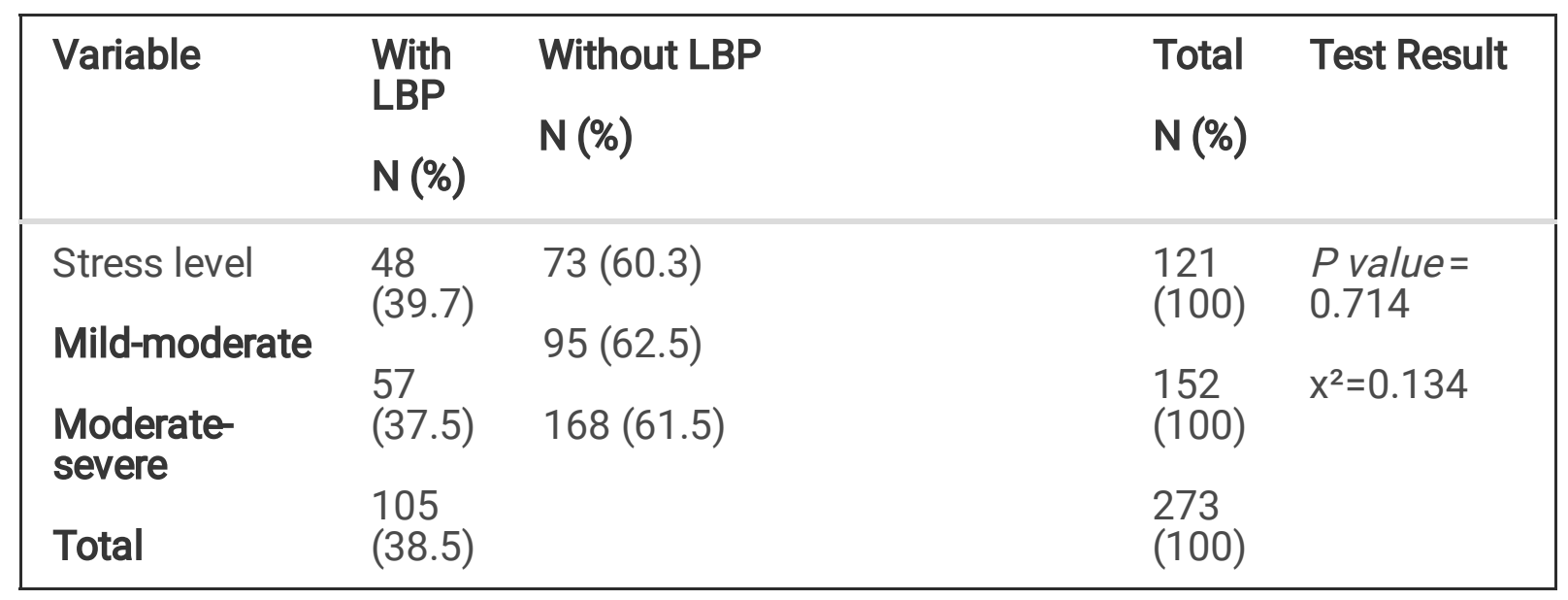

The prevalence of LBP was higher in patients with more work experience and older individuals ( $P$ value $<$ 0.001). However, no association was found between BMI and total stress score with the prevalence of LBP [Table 2].

In order to control confounding factors, variables that might have influenced the final results were entered in a logistic regression model [Tables 3]. It should be noted that due to the strong correlation between age and the duration of employment, logistic regression was performed in 2 different age categories: less than 40 years old and equal to or more than 40 years old.

Table 2 - The Comparison of Quantitative Variables in Patients with and without LBP

\begin{tabular}{|llll|}
\hline Variable & $\begin{array}{l}\text { Without LBP } \\
(\text { Mean } \pm \text { SD })\end{array}$ & $\begin{array}{l}\text { With LBP } \\
(\text { Mean } \pm \text { SD })\end{array}$ & Test Result \\
\hline Age & $38.2 \pm 6.4$ & $41.8 \pm 5.5$ & $T=4.83 \quad P$ value $<0.001$ \\
\hline Work experience & $38.2 \pm 6.4$ & $41.8 \pm 5.5$ & $T=4.83 P$ value $<0.001$ \\
\hline BMI & $25.8 \pm 3.2$ & $26.4 \pm 3$ & $T=1.6 P$ value $=0.099$ \\
\hline Total Stress Score & $185.4 \pm 25.8$ & $180.97 \pm 28.6$ & $\mathrm{~T}=-1.3 P$ value $=0.182$ \\
\hline
\end{tabular}


Table 3

Relationship between total LBP* and Occupation, Duration of Employment, and Total Stress Score According to Age Category in the Regression Model

\begin{tabular}{|c|c|c|c|c|c|c|c|c|}
\hline & & $40 \leq$ & & & & $<40$ & & \\
\hline variables & $\begin{array}{l}P \\
\text { value }\end{array}$ & $\begin{array}{l}\mathrm{Cl} \\
95 \%\end{array}$ & OR & coefficient & $\begin{array}{l}P \\
\text { value }\end{array}$ & $\begin{array}{l}\mathrm{Cl} \\
95 \%\end{array}$ & OR & coefficient \\
\hline $\begin{array}{l}\text { Occupation } \\
\text { Industrial }\end{array}$ & 0.453 & $\begin{array}{l}2.78- \\
0.63\end{array}$ & 1.32 & 0.283 & 0.080 & $\begin{array}{l}6.60- \\
0.90\end{array}$ & 2.43 & 0.891 \\
\hline Administrative & - & - & 1 & 0 & - & - & 1 & 0 \\
\hline $\begin{array}{l}\text { Duration of } \\
\text { employment }\end{array}$ & 0.235 & $\begin{array}{l}1.22- \\
0.95\end{array}$ & 1.08 & 0.077 & 0.002 & $\begin{array}{l}1.31- \\
1.06\end{array}$ & 1.18 & 0.169 \\
\hline Total Stress Score & 0.100 & $\begin{array}{l}1.00- \\
0.97\end{array}$ & 0.98 & -0.011 & 0.208 & $\begin{array}{l}1.00- \\
0.97\end{array}$ & 0.98 & -0.011 \\
\hline
\end{tabular}

The results showed that in the age group under 40 years old with each year increase in the duration of employment, the odds of the developing LBP is raised by 0.18 .

In the next step, Discogenic low back pain (DLBP) and non-specific low back pain (NSLBP) were entered into the logistic regression model separately [Tables 4 and 5]. Similar to the overall pattern of LBP, in the under 40 years old group with each year increase in the duration of employment, the odds of the development of NSLBP and DLBP were raised by 0.14 and 0.31 , respectively.

Table 4

Relationship between DLBP* and occupation, duration of employment, and Total Stress Score According to Age Category in the Regression Model

\begin{tabular}{|c|c|c|c|c|c|c|c|c|}
\hline & & $40 \leq$ & & & & $<40$ & & \\
\hline variables & $\begin{array}{l}\mathrm{P} \\
\text { value }\end{array}$ & $\mathrm{Cl} 95 \%$ & OR & coefficient & $\begin{array}{l}P \\
\text { value }\end{array}$ & $\mathrm{Cl} 95 \%$ & OR & coefficient \\
\hline Occupation & 0.312 & $6.08-$ & 1.84 & 0.615 & - & - & - & - \\
\hline $\begin{array}{l}\text { Industrial } \\
\text { Administrative }\end{array}$ & - & & 1 & 0 & - & - & - & - \\
\hline $\begin{array}{l}\text { duration of } \\
\text { employment }\end{array}$ & 0.463 & $\begin{array}{l}1.37- \\
0.86\end{array}$ & 1.09 & 0.087 & 0.010 & $\begin{array}{l}1.62- \\
1.07\end{array}$ & 1.31 & 0.277 \\
\hline $\begin{array}{l}\text { Total Stress } \\
\text { Score }\end{array}$ & 0.174 & $\begin{array}{l}1.00- \\
0.96\end{array}$ & 0.98 & -0.014 & 0.126 & $\begin{array}{l}1.00- \\
0.94\end{array}$ & 0.97 & -0.023 \\
\hline
\end{tabular}


Table 5

Relationship between NSLBP* and occupation, duration of employment, and Total Stress Score According to Age Category in the Regression Model

\begin{tabular}{|c|c|c|c|c|c|c|c|c|}
\hline & & $40 \leq$ & & & & $<40$ & & \\
\hline variables & $\begin{array}{l}\mathrm{P} \text { - } \\
\text { value }\end{array}$ & $\mathrm{Cl} 95 \%$ & OR & coefficient & $\begin{array}{l}\mathrm{P}- \\
\text { value }\end{array}$ & $\mathrm{Cl} 95 \%$ & OR & coefficient \\
\hline $\begin{array}{l}\text { Occupation } \\
\text { Industrial }\end{array}$ & 0.611 & $\begin{array}{l}2.71- \\
0.55\end{array}$ & 1.22 & 0.206 & 0.584 & $\begin{array}{l}0.47- \\
3.79\end{array}$ & 1.33 & 0.292 \\
\hline Administrative & - & - & 1 & 0 & - & - & 1 & - \\
\hline $\begin{array}{l}\text { duration of } \\
\text { employment }\end{array}$ & 0.254 & $\begin{array}{l}1.24- \\
0.94\end{array}$ & 1.08 & 0.080 & 0.020 & $\begin{array}{l}1.28- \\
1.02\end{array}$ & 1.14 & 0.137 \\
\hline $\begin{array}{l}\text { Total Stress } \\
\text { Score }\end{array}$ & 0.127 & $\begin{array}{l}1.00- \\
0.97\end{array}$ & 0.98 & -0.012 & 0.466 & $\begin{array}{l}1.01- \\
0.97\end{array}$ & 0.99 & -0.007 \\
\hline
\end{tabular}

In the mentioned statistical models, the risk of suffering from LBP (total, non-specific. and discogenic) was higher in the industrial workers compared to the administrative group, however, this relation was not statistically significant. It should be mentioned that no significant statistical association was observed between LBP and total stress level in neither age groups.

\section{Discussion}

In this study, the association of LBP with personal, occupational and psychosocial factors was investigated. Our findings demonstrated no significant association between LBP and sex, smoking, neuropsychological disorders, body mass index, type of job, shiftwork, total stress score and stress intensity. Nevertheless, our results demonstrated that LBP was statistically correlated with age and the duration of employment.

The annual prevalence of LBP in the steel industry in our study was $38.5 \%$. The prevalence rate of LBP in different studies was between $11 \%$ and $65 \%$. This notable difference in prevalence rate can be justified by research method, different job categories, demographic characteristics, LBP definition and worker support systems and insurance (11-13).

According to our findings, a significant relationship was found between LBP and age, which was mentioned in numerous previous studies $(14,15)$; however, this relationship was not confirmed in some studies $(16,17)$. The acceleration of degenerative changes due to aging may explain the higher prevalence of LBP in older people.

In our study, no association was found between LBP and smoking, which is in line with previous studies (17). However, smoking is reported to be a risk factor for LBP in some other studies $(15,18,19)$. 
Interestingly, a meta-analysis, which was comprised of 27 cross-sectional and 13 cohort studies, demonstrated that smoking cessation can relatively decrease the risk of LBP but, cannot eliminate it (20). It is noteworthy that the very low rate of smoking in our sample size might be because of the reluctance of our participants for honest disclosure of the issue due to the probable repercussions, justifying the discrepancy between our results and previous studies.

According to our study, LBP and work experience are interrelated which is in parallel with previous research $(14,18)$. The relationship between LBP and the duration of employment was statistically significant in the under 40 years old group. Since people enter the industry in the second or third decade of their life, this age period is when individuals are gaining experience in their work environment through trial and error, thus they are more prone to health-related issues. Entering the fourth decade of life, workers have gained the essential experience and knowledge regarding their occupational setting, duties, and job-related hazards; therefore, the incidence of health problems is expected to diminish with the increase in age and work experience.

In the present study, no association was found between LBP and work type (Industrial or administrative). Similarly, a systematic review conducted by Kwon et al. demonstrated no conclusive evidence regarding a relationship between LBP and work type (21). Moreover, a meta-analysis by Taylor et al. showed that LBP incidence in the general population is similar to different occupational groups (22). On the other hand, a meta-analysis conducted by Griffith et al. illustrated a moderate relation between mechanical workplace risk factors and LBP however, the essence of this association could not be elucidated (23). Furthermore, another study reported that LBP was associated with carrying heavy loads (24).

Our results demonstrated that the total stress score in workers with LBP is similar to healthy individuals. However, this finding is controversial and studies are not conclusive in this regard. Ghaffari and colleagues investigated the relationship between psychosocial factors and LBP using the Nordic questionnaire. Their results showed that among all psychosocial characteristics, only a monotonous job is a risk factor for LBP (12). Kresal et al. showed a significant relationship between LBP and psychosocial stress in professional drivers (24). Similarly, Habibi et al. demonstrated a significant association between LBP and psychosocial factors such as job demand, job content, social support, and job control in nurses (25). Moreover, the incidence of LBP was found to be correlated with job insecurity, unfriendly working environment and job-family incongruity (26). Conversely, Boughattas and colleagues found no relationship between psychosocial factors and LBP in nurses, which is in line with the results of several other studies (27-29). As it was mentioned, the results of previous studies are not congruent regarding this issue; moreover, in the majority of them, job stress was not inspected separately and via standard questionnaires. These studies were conducted using self-reports of some psychosocial factors such as job satisfaction, social support, personality characteristics, and the individual perception of job control. However, we specifically investigated job stress in 6 different domains of workload, role ambiguity, role insufficiency, role conflict, responsibility, and physical environment, based on a standard questionnaire. However, it is worth noting that the term "stress" is a general concept that incorporates all stressful experiences during work and personal life of an individual. Therefore, observing no relationship between 
job stress and LBP does not preclude its impact on the development and chronicity of LBP. The influence of other psychosocial factors in the process of managing this disease should be considered.

In a systematic review by Mehrdad et al. on the Iranian population, the prevalence of LBP was similar in both males and females which is parallel to our results and previous studies $(17,24)$. Nevertheless, some studies reported a relationship between gender and $\operatorname{LBP}(15,19)$. This discrepancy may be due to differences in study populations and occupation.

In a study on 1439 steel industry workers, a noticeable relationship was reported between BMI and LBP (16). Similarly, a study conducted on 245 nurses showed that with every unit increase in BMI from 27 $\mathrm{kg} / \mathrm{m}^{2}$, the risk of developing LBP will be roughly doubled (30). Although LBP was more common in patients with higher BMI in our study, this difference was not statistically significant.

In this research, no relationship was observed between shiftwork and LBP which is similar to the results of Trezi et al. study (17). However, a direct association between LBP and shiftwork has also been reported (23). Thus, revealing the true nature of the relationship between LBP and shiftwork requires further studies.

Our study had several limitations. For instance, because this was a cross-sectional study, the causal relationship between LBP and some of the factors is not conclusive. Moreover, the healthy worker effect could have also imposed some limitations on the relationship between some risk factors and LBP. Furthermore, self-reported answers might have affected the results. However, we carried out a comprehensive investigation of all three groups of possible LBP risk factors (personal, occupational, and psychosocial) and applied standard questionnaires to increase the validity of our results.

\section{Conclusion}

In this study, no association was found between LBP and job stress as well as other occupational factors. Among the personal factors, LBP only had a significant relationship with age and the duration of employment, a relation that was prominently significant in the under 40 year old group. Therefore, it appears that preventive measures targeting LBP are better to be more focused on lower age groups, especially in the limitations of required resources.

\section{Declarations}

Ethics approval and consent to participate: The protocols in this study conformed to the ethical guidelines of the 2013 Declaration of Helsinki. Informed consent was obtained from participants prior to the initiation of study. The present study was a result of a thesis with the serial number of P8705 approved by Mashhad University of Medical Sciences. The proposal was submitted to the Mashhad University of Medical Sciences and received the full approval of the ethics committee (Code: IR.MUMS.fm.REC.1395.586(. 
Consent for publication: Not applicable

Availability of data and materials: The datasets used and/or analyzed during the current study are available from the corresponding author on reasonable request.

Competing interests: The authors declare that they have no competing interests

Funding: The study has been conducted with no funds from external sources.

Authors' contributions: E. Rafeemanesh and P.Pakdaman and F.Ahmadi wrote the main manuscript text. H.Esmaily did the data analysis.All authors reviewed the manuscript.

Acknowledgements: The authors greatly appreciate the cooperation of all the steel factory staff participating in this research project.

\section{References}

1. Sakai T, Sairyo K, Suzue N, Kosaka H, Yasui N. Incidence and etiology of lumbar spondylolysis: review of the literature. Journal of orthopaedic science. 2010;15(3):281-8.

2. LaDou J, Harrison R. Current occupational \& environmental medicine: McGraw-Hill New York; 2007.

3. Peykari N, Hashemi H, Dinarvand R, Haji-Aghajani M, Malekzadeh R, Sadrolsadat A, et al. National action plan for non-communicable diseases prevention and control in Iran; a response to emerging epidemic. Journal of Diabetes \& Metabolic Disorders. 2017;16(1):3.

4. Forouzanfar MH, Sepanlou SG, Shahraz S, BESc PN, Pourmalek F, Lozano R, et al. Evaluating causes of death and morbidity in Iran, global burden of diseases, injuries, and risk factors study 2010. Archives of Iranian medicine. 2014;17(5):304.

5. Urquhart DM, Berry P, Wluka AE, Strauss BJ, Wang Y, Proietto J, et al. 2011 Young Investigator Award winner: Increased fat mass is associated with high levels of low back pain intensity and disability. Spine. 2011;36(16):1320-5.

6. Braddom RL. Physical medicine and rehabilitation e-book: Elsevier Health Sciences; 2010.

7. Mohseni-Bandpei MA, Fakhri M, Ahmad-Shirvani M, Bagheri-Nesami M, Khalilian A. Risk factors for low back pain in nurses. Journal of Mazandaran University of Medical Sciences. 2006;15(50):11824.

8. Palmer KT, Brown I. Fitness for work: the medical aspects: Oxford university press; 2007.

9. Sharifian S, Aminian O, Kiyani M, Barouni S, AMIRI F. The evaluation of the degree of occupational stress and factors influencing it in forensic physicians working in legal medicine organization in Tehran-autumn of 2005. 2006.

10. Choobineh A, Lahmi M, Shahnavaz H, Khani Jazani R, Hosseini M. Musculoskeletal symptoms as related to ergonomic factors in Iranian hand-woven carpet industry and general guidelines for 
workstation design. International journal of occupational safety and ergonomics. 2004;10(2):15768.

11. Lee P, Helewa A, Goldsmith CH, Smythe HA, Stitt LW. Low back pain: prevalence and risk factors in an industrial setting. The Journal of rheumatology. 2001;28(2):346-51.

12. Ghaffari $M$, Alipour $A$, Jensen I, Farshad AA, Vingard E. Low back pain among Iranian industrial workers. Occupational Medicine. 2006;56(7):455-60.

13. Hussain T. Musculoskeletal symptoms among truck assembly workers. Occupational Medicine. 2004;54(8):506-12.

14. Xu G, Pang D, Liu F, Pei D, Wang S, Li L. Prevalence of low back pain and associated occupational factors among Chinese coal miners. BMC public health. 2012;12(1):149.

15. Alkherayf F, Agbi C. Cigarette smoking and chronic low back pain in the adult population. Clinical and Investigative Medicine. 2009:E360-E7.

16. Aghilinejad M, Choobineh A, Sadeghi Z, Nouri M, Ahmadi AB. Prevalence of musculoskeletal disorders among Iranian steel workers. Iranian Red Crescent Medical Journal. 2012;14(4):198.

17. Terzi R, Altın $F$. The prevalence of low back pain in hospital staff and its relationship with chronic fatigue syndrome and occupational factors. Agri: Agri (Algoloji) Dernegi'nin Yayin organidir $=$ The journal of the Turkish Society of Algology. 2015;27(3):149-54.

18. Firmanita SD, Rosdiana I, Indrayani UD. The Correlation between Duration of Employment, Body Posture and Smoking Habit on Low Back Pain Incidence An Analytic Observational Study Among Taxi Driver in Semarang Municipality. Sains Medika: Jurnal Kedokteran dan Kesehatan. 2015;6(1):17-20.

19. Capkin E, Karkucak M, Cakırbay H, Topbas M, Karaca A, Köse M, et al. The prevalence and risk factors of low back pain in the eastern Black Sea region of Turkey. Journal of back and musculoskeletal rehabilitation. 2015;28(4):783-7.

20. Shiri R, Karppinen J, Leino-Arjas P, Solovieva S, Viikari-Juntura E. The association between smoking and low back pain: a meta-analysis. The American journal of medicine. 2010;123(1):87. e7-. e35.

21. Kwon B, Roffey D, Bishop P, Dagenais S, Wai E. Systematic review: occupational physical activity and low back pain. Occupational medicine. 2011;61(8):541-8.

22. Taylor JB, Goode AP, George SZ, Cook CE. Incidence and risk factors for first-time incident low back pain: a systematic review and meta-analysis. The Spine Journal. 2014;14(10):2299-319.

23. Griffith LE, Shannon HS, Wells RP, Walter SD, Cole DC, Côté P, et al. Individual participant data metaanalysis of mechanical workplace risk factors and low back pain. American journal of public health. 2012;102(2):309-18.

24. Kresal F, Suklan J, Roblek V, Jerman A, Mesko M. Psychosocial risk factors for low back pain and absenteeism among Slovenian professional drivers. Central European Journal of Public Health. 2017. 
25. Habibi E, Pourabdian S, Atabaki AK, Hoseini M. Evaluation of work-related psychosocial and ergonomics factors in relation to low back discomfort in emergency unit nurses. International journal of preventive medicine. 2012;3(8):564.

26. Yang H, Haldeman S, Lu M-L, Baker D. Low back pain prevalence and related workplace psychosocial risk factors: a study using data from the 2010 National Health Interview Survey. Journal of manipulative and physiological therapeutics. 2016;39(7):459-72.

27. Ramond-Roquin A, Bouton C, Bègue C, Petit A, Roquelaure $Y$, Huez J-F. Psychosocial risk factors, interventions, and comorbidity in patients with non-specific low back pain in primary care: need for comprehensive and patient-centered care. Frontiers in medicine. 2015;2:73.

28. Jansen J, Morgenstern H, Burdorf A. Dose-response relations between occupational exposures to physical and psychosocial factors and the risk of low back pain. Occupational and environmental medicine. 2004;61(12):972-9.

29. Boughattas W, El Maalel O, Maoua M, Bougmiza I, Kalboussi H, Brahem A, et al. Low back pain among nurses: prevalence, and occupational risk factors. Occupational Diseases and Environmental Medicine. 2017;5(1):26-37.

30. Sadeghian F, Javanmard M, Khosravi A, Adelnia S. An epidemiological survey of Low back pain and its relationship with occupational and personal factors among nursing personnel at hospitals of Shahrood Faculty of Medical Sciences. ISMJ. 2005;8(1):75-82. 